\title{
Desempenho e rendimento de carcaça de bovinos mestiços alimentados com diferentes volumosos e fontes protéicas ${ }^{1}$
}

\section{Fernanda Macitelli ${ }^{2}$, Telma Teresinha Berchielli ${ }^{3}$, Juciléia Aparecida da Silva Morais ${ }^{2}$, Roselene Nunes da Silveira ${ }^{2}$, Roberta Carrilho Canesin²}

\footnotetext{
1 Projeto financiado pela FAPESP.

2 Pós-Graduação em Zootecnia, FCAV/Unesp - Jaboticabal (SP).

${ }^{3}$ FCAVIUnesp - Jaboticabal SP. Pesquisador do CNPq.
}

RESUMO - Quarenta bovinos machos, com 30 meses de idade e $371 \mathrm{~kg}$, foram distribuídos em um delineamento em blocos casualizado com esquema fatorial 3 x 3, para avaliar o desempenho e rendimento de carcaça quando alimentados com diferentes fontes protéicas (Amiferm, uréia e farelo de soja) e volumosos (pastagem de capim-braquiária, cana-de-açúcar e silagem de milho). As dietas foram balanceadas para conterem níveis semelhantes de EM e PB. A interação volumoso x fonte de $\mathrm{N}$ não foi significativa para nenhum dos parâmetros estudados. O ganho de peso vivo diário (GPV/dia) dos animais alimentados com cana-de-açúcar $(0,83 \mathrm{~kg})$ não diferiu dos mantidos em pastagem $(0,82 \mathrm{~kg})$, mas ambos foram menores que dos animais alimentados com silagem de milho (1,09 kg). As diferentes fontes de $\mathrm{N}$ proporcionaram GPV/dia semelhantes, com valores de 0,94; 0,83 e 0,97 kg, para os animais que receberam uréia, Amiferm e farelo de soja, respectivamente. As dietas contendo farelo de soja proporcionaram maior ganho de carcaça diário $(0,57 \mathrm{~kg})$ em relação ao uso de Amiferm, não diferindo da uréia $(0,55 \mathrm{~kg})$. Não houve diferença entre volumosos e fontes nitrogenadas para rendimento de carcaça, rendimento de carcaça do corpo vazio, rendimento de carcaça do ganho de peso e espessura de gordura, com média de 51,03\%, 54,49\%, 60,10\% e 8,5 mm, respectivamente. O uso de Amiferm proporcionou ganhos de peso e rendimento de carcaça semelhantes às demais fontes protéicas.

Palavras-chave: Amiferm, Brachiaria brizantha, cana-de-açúcar, farelo de soja, silagem de milho, uréia

\section{Performance and carcass dressing in crossbreed steers fed different forage and nitrogen sources}

\begin{abstract}
Forty steers averaging $371 \mathrm{~kg}$ BW were allotted to a randomized block design, in a factorial scheme $3 \mathrm{x} 3$ to evaluate the effect of feeding different protein sources (urea, amiferm, soybean meal) and forage (sugar cane, corn silage and pasture Bracharia brizantha) on performance and carcass dressing. Diets were formulated to contain similar ME and CP protein levels. Forage and nitrogen source interaction was not significant for all studied factors. Daily live weight (LWG/ day) of animal fed sugar cane $(0.83 \mathrm{~kg})$ did not differ from those fed in pasture $(0.82 \mathrm{~kg})$, but both were different from corn silage $(1.09 \mathrm{~kg})$. The different protein sources resulted in similar LWG/day, with value of $0.94 ; 0.83$ e $0.97 \mathrm{~kg}$, for urea, Amiferm and soybean meal, respectively. Soybean meal diets showed higher daily carcass gain $(0.57 \mathrm{~kg})$ in relation to Amiferm $(0.46 \mathrm{~kg})$ but both nitrogen sources did not differ from urea $(0.55 \mathrm{~kg})$. There was no difference among forage and nitrogen sources for carcass dressing, carcass dressing in function of empty weight (\%EBW), carcass yield of weight gain and fat layer, mean of 51.03\%, 54.49\%, 60.10\% e $8.5 \mathrm{~mm}$, respectively. The use of Amiferm provided weight gain and carcass dressing similar to the others nitrogen sources.
\end{abstract}

Key Words: Amiferm, Brachiaria brizantha, corn silage, soybean meal, sugar cane, urea

\section{Introdução}

O confinamento e a suplementação da dieta de animais mantidos em pastagem são tecnologias potenciais para aumentar a eficiência dos sistemas de produção de proteína de origem animal, principalmente em épocas desfavoráveis ao crescimento da forragem.
As respostas obtidas com a prática da suplementação nesses sistemas dependem, entre outros fatores, da qualidade do concentrado ofertado, uma vez que será o responsável pelo fornecimento, ao animal, de nutrientes deficientes na dieta basal, limitantes do ganho de peso. Fatores como alteração nos custos de produção também são muito importantes e, muitas vezes, são 
decisivos para a tomada de decisão da implantação destas técnicas.

Nesse sentido, a suplementação nitrogenada é, geralmente, a de maior custo; por isso, a substituição de fontes de proteína verdadeira, presente principalmente nos grãos, por fontes de nitrogênio não-protéico (NNP) ou fontes alternativas constitui-se em uma alternativa para redução dos custos da alimentação e obtenção de bons ganhos de peso de bovinos confinados ou suplementados em pastagem.

Em razão de a amônia ser a fonte preferencial de nitrogênio para as bactérias celulolíticas (Russel et al., 1992), o fornecimento de NNP pode se tornar uma opção conveniente para melhorar o consumo e a digestão de forragens de baixa qualidade e deficientes em nitrogênio (Siebert \& Hunter, 1982), desde que acompanhada de adequada disponibilidade de forragem. Além disso, segundo Owens \& Zinn (1988), em dietas pobres em nitrogênio, a fixação do $\mathrm{N}$ amoniacal às moléculas de carbono pelas bactérias ruminais ocorre via ação da enzima glutamina sintetase. Essa enzima necessita de um mol de ATP para cada mol de amônia fixada. Como conseqüência, quando é baixa a concentração de $\mathrm{N}$ amoniacal no rúmen, há diminuição da eficiência de crescimento microbiano, pois moléculas de ATP são desviadas do crescimento para o processo de captação da amônia pelas bactérias ruminais que sintetizam essa enzima. Dessa forma, o fornecimento de $\mathrm{N}$ prontamente disponível em situações de baixa concentração de $\mathrm{N}$ no rúmen favorece o desenvolvimento microbiano e, conseqüentemente, a atividade ruminal.

Por outro lado, a produção de ácidos graxos de cadeia curta ramificada (ácido isobutírico, isovalérico e 2-metilbutírico) e linear (ácido valérico) pela deaminação de aminoácidos oriundos de proteína verdadeira é necessária para o crescimento de bactérias celulolíticas e importante em dietas de baixa qualidade (Owens \& Zinn, 1988).

Todos esses efeitos no metabolismo ruminal afetam diretamente o desempenho animal, em decorrência de mudanças na quantidade e qualidade dos produtos de fermentação formados no rúmen. Assim, o sucesso da prática depende da fonte de nitrogênio utilizada, da qualidade e quantidade do volumoso basal, da categoria animal e, principalmente, da interação desses fatores.

Como fonte de proteína verdadeira, têm sido pesquisados vários alimentos, com comprovada eficácia no desempenho animal, mas como fonte de NNP poucos são os substitutos encontrados para a uréia. Alguns estudos sugerem que o Amiferm possa ser utilizado como fonte de NNP (Macitelli et al., 2003a,b). O Amiferm é um subproduto industrial, obtido na fase final da produção do sal glutamato monossódico, na forma líquida, a partir da fermentação do melaço da cana-de-açúcar por bactérias, apresentando como principal característica a alta concentração de nitrogênio (8 a 10\%, dos quais 30\% se encontram na forma amoniacal). Por se tratar de um subproduto industrial produzido no Brasil, é importante a realização de estudos em condições brasileiras, para verificar o potencial de uso deste subproduto na produção de bovinos, uma vez que não se dispõe de dados acerca de sua utilização na alimentação de ruminantes.

Os alimentos oferecidos durante a terminação têm efeito significativo nas diferenças observadas no rendimento de carcaça em bovinos, em virtude das diferenças que ocorrem no desenvolvimento do trato digestório. O rendimento diminui em animais submetidos a dietas compostas por alimentos de baixa velocidade de passagem pelo trato digestório ou que necessitam de maior consumo de alimentos para suprir as exigências fisiológicas (Di Marco, 1998). Nesses casos, ocorre maior desenvolvimento do rúmenretículo, resultando em animais com maior peso do trato digestório cheio e vazio, assim como maior quantidade de couro para envolver maior arqueamento de costelas (Vaz et al., 2001).

Objetivou-se com este trabalho avaliar o potencial de utilização do resíduo da produção do glutamato monossódico como fonte de nitrogênio não-protéico (NNP), comparando-o com uréia e uma fonte de proteína verdadeira (farelo de soja), sobre o desempenho e as características das carcaças de bovinos alimentados com diferentes volumosos.

\section{Material e Métodos}

O trabalho foi desenvolvido no Setor de Digestibilidade, pertencente ao Departamento de Zootecnia da Faculdade de Ciências Agrárias e Veterinárias da Universidade Estadual Paulista, em Jaboticabal-SP.

Foram utilizados 40 novilhos mestiços Holandês-Zebu, com idade e peso médios iniciais de 30 meses e $371 \mathrm{~kg}$, respectivamente. Os animais foram divididos em quatro blocos, em função do peso, de modo que um animal de cada bloco foi abatido no início do período experimental para servirem como referência aos demais, que foram abatidos ao final de quatro períodos experimentais de 28 dias cada.

O período de adaptação total foi de 21 dias; nos primeiros sete dias, os animais que seriam abatidos como referência permaneceram em pastagem, juntamente com os demais, que foram castrados, vermifugados e identificados com brinco. A adaptação às instalações, ao manejo e à alimen- 
tação ocorreu nos 14 dias seguintes. Nesse período, os animais-referência foram abatidos, enquanto os que permaneceram nos tratamentos que continham uma fonte de NNP receberam doses crescentes de uréia e Amiferm e aqueles mantidos em pastagem foram adaptados a receber o concentrado em baias individuais pela manhã.

Doze animais foram mantidos em 2,0 ha de pastagem de Brachiaria brizantha Hochst Stapf cv. Marandu, doze foram alimentados com cana-de-açúcar picada e o restante com silagem de milho. Os animais que receberam os dois últimos volumosos permaneceram confinados em baias individuais semicobertas, com cocho individual e bebedouro comum a duas baias. Para cada volumoso, os animais foram distribuídos aleatoriamente em três lotes (de quatro animais cada), de acordo com as fontes protéicas: cana-de-açúcar + uréia, cana-de-açúcar + Amiferm, cana-de-açúcar + farelo de soja, silagem de milho + uréia, silagem de milho + Amiferm, silagem de milho + farelo de soja, pastagem + uréia, pastagem + Amiferm e pastagem + farelo de soja.

As dietas (Tabela 1) foram balanceadas conforme AFRC (1995) para apresentarem níveis semelhantes de energia metabolizável estimada (100 MJ/animal/dia) e proteína bruta (1 kg/animal/dia). A quantidade de uréia no concentrado foi fixada (120 g) e, a partir desta, calculou-se a quantidade de Amiferm, que correspondeu ao mesmo teor de nitrogênio presente na uréia (580 mL).
A relação volumoso:concentrado estabelecida na formulação para os tratamentos com cana-de-açúcar e pastagem foi de $60 \%$ de volumoso e $40 \%$ de concentrado e, para os tratamentos com silagem de milho, $70 \%$ de volumoso e $30 \%$ de concentrado. A ingestão de MS do concentrado foi estimada em $0,64 \%$ do peso vivo para os animais alimentados com silagem de milho e $1 \%$ do peso vivo para os alimentados com cana-de-açúcar e com pastagem.

As dietas foram recalculadas após os dois primeiros períodos experimentais, em razão do ganho de peso dos animais, mas foram mantidas constantes as relações volumoso:concentrado e a ingestão de MS dos concentrados em porcentagem do peso vivo.

Os animais foram pesados a cada 28 dias, no período da manhã, antes do fornecimento das rações, sem jejum prévio, para determinação do ganho de peso (GP).

Os animais mantidos em pastagem eram recolhidos todos os dias, das 8 às $13 \mathrm{~h}$, e recebiam o concentrado em baias individuais. A ingestão de MS de cana-de-açúcar, silagem de milho e concentrado (Tabela 2) foi avaliada pelo controle diário da quantidade de alimento ofertada e das sobras no cocho. Para se estimar a ingestão de MS da pastagem, calculou-se a energia necessária para manutenção e ganho de peso, a partir do ganho de peso obtido, segundo o AFRC (1995). A partir do cálculo da ingestão de energia metabolizável do concentrado e de sua ingestão de

Tabela 1 - Composição centesimal dos ingredientes no concentrado

Table 1 - Percentage composition of the ingredient in concentrate

Composição dos ingredientes (\%)

Ingredient composition

\begin{tabular}{|c|c|c|c|c|}
\hline \multirow[t]{2}{*}{ Item } & \multicolumn{2}{|c|}{$\begin{array}{l}1^{\mathrm{o}} \text { e } 2^{\mathrm{o}} \text { períodos } \\
1^{\text {st }} \text { and } 2^{\text {nd }} \text { periods }\end{array}$} & \multicolumn{2}{|c|}{$\begin{array}{l}3^{0} \text { e } 4^{\circ} \text { períodos } \\
3^{\text {rd }} \text { and } 4^{\text {th }} \text { periods }\end{array}$} \\
\hline & $\begin{array}{l}\text { Milho } \\
\text { Corn }\end{array}$ & $\begin{array}{l}\text { Farelo de soja } \\
\text { Soybean meal }\end{array}$ & $\begin{array}{l}\text { Milho } \\
\text { Corn }\end{array}$ & $\begin{array}{c}\text { Farelo de soja } \\
\text { Soybean meal }\end{array}$ \\
\hline $\begin{array}{l}\text { Cana-de-açúcar + Uréia }{ }^{1} \\
\text { Sugarcane + Urea }\end{array}$ & 84,7 & 15,3 & 93,0 & 7,0 \\
\hline $\begin{array}{l}\text { Cana-de-açúcar + Amiferm² } \\
\text { Sugarcane + Amiferm }\end{array}$ & 84,7 & 15,3 & 93,0 & 7,0 \\
\hline $\begin{array}{l}\text { Cana-de-açúcar + Farelo de soja } \\
\text { Sugarcane + Soybean meal }\end{array}$ & 68,0 & 32,0 & 74,0 & 26,0 \\
\hline $\begin{array}{l}\text { Silagem de milho + Uréia }{ }^{1} \\
\text { Corn silage + Urea }\end{array}$ & 93,6 & 6,4 & 100,0 & - \\
\hline $\begin{array}{l}\text { Silagem de milho }+ \text { Amiferm }^{2} \\
\text { Corn silage }+ \text { Amiferm }\end{array}$ & 93,6 & 6,4 & 100,0 & - \\
\hline $\begin{array}{l}\text { Silagem de milho + Farelo de soja } \\
\text { Corn silage + Soybean meal }\end{array}$ & 67,0 & 33,0 & 76,0 & 24,0 \\
\hline $\begin{array}{l}\text { Pastagem + Uréia }{ }^{1} \\
\text { Pasture + Urea }\end{array}$ & 84,7 & 15,3 & 93,0 & 7,0 \\
\hline $\begin{array}{l}\text { Pastagem + Amiferm }{ }^{2} \\
\text { Pasture + Amiferm }\end{array}$ & 84,7 & 15,3 & 93,0 & 7,0 \\
\hline $\begin{array}{l}\text { Pastagem + Farelo de soja } \\
\text { Pasture + Soybean meal }\end{array}$ & 68,0 & 32,0 & 74,0 & 26,0 \\
\hline
\end{tabular}

${ }^{1}$ Fornecimento de $120 \mathrm{~g} /$ anim.d de uréia; ${ }^{2}$ Substituição da uréia por $580 \mathrm{~mL}$ de Amiferm.

${ }^{1}$ Supply of $120 \mathrm{~g} /$ anim.l d of urea; ${ }^{2}$ Substitution of urea by $580 \mathrm{~mL}$ of Amiferm. 
MS, supondo uma concentração energética da dieta de 13,8 MJ, por diferença obteve-se a ingestão de energia metabolizável que supostamente viria do capim. Este valor, dividido por 8 MJ (provável concentração energética da pastagem), resulta na quantidade de MS de pastagem consumida.

A determinação da massa de forragem da Brachiaria (Tabela 3) foi realizada no início de cada período experimental por cortes de dez áreas $\left(1 \mathrm{~m}^{2}\right)$, escolhidas ao acaso e cortadas a, aproximadamente, $15 \mathrm{~cm}$ do solo, conforme proposto por McMenimam (1997).

A amostragem do capim foi realizada semanalmente por simulação manual de pastejo, após observação prévia do comportamento ingestivo dos animais. A cana-de-açúcar e a silagem de milho, assim como os concentrados, foram amostradas semanalmente e congeladas. No final de cada período experimental, estras amostras foram homogeneizadas, secas, moídas e analisadas.

Nas amostras de alimento, foram determinados os teores de MS, matéria mineral, EE e nitrogênio amoniacal, segundo metodologia descrita em Silva (1990); FDN e FDA, conforme recomendações propostas por Van Soest et al. (1991); e nitrogênio total (NT) pelo método de Dumas em aparelho Leco 528 LC (Etheridge et al., 1998). A análise da MS do Amiferm foi realizada pelo método de destilação por tolueno, segundo Silva (1990).

Os quatro animais que serviram como referência aos demais foram abatidos no matadouro municipal de Monte Alto-SP. Ao término dos quatro períodos experimentais, todos os animais foram submetidos a jejum alimentar de 14 horas, com livre acesso à água, e abatidos no frigorífico Serv-Carne, localizado no município de Matão-SP.

O abate foi realizado por concussão cerebral e sangria, feita pela seção da veia jugular. Todo o procedimento de abate e coleta de dados foram idênticos aos dos animais referência abatidos no início do experimento.

Após o abate de cada animal, foram coletados os seguintes dados:

- Rendimento de carcaça (RCar): após a separação da cabeça, retirada do couro e completa evisceração, as carcaças foram divididas com serra elétrica, obtendo-se duas meia-

Tabela 2 - Valores médios dos nutrientes nos concentrados e nos volumosos (\% MS)

Table 2 - $\quad$ Mean values of nutrients in the concentrates and in the forages (\% DM)

\begin{tabular}{|c|c|c|c|c|c|c|}
\hline \multirow[t]{2}{*}{ Item } & \multirow[t]{2}{*}{$\begin{array}{l}\text { MS } \\
D M\end{array}$} & \multicolumn{5}{|c|}{$\begin{array}{l}\text { Nutriente } \\
\text { Nutrient }\end{array}$} \\
\hline & & $\begin{array}{l}\mathrm{PB} \\
\mathrm{CP}\end{array}$ & $\begin{array}{l}\mathrm{EE} \\
E E\end{array}$ & $\begin{array}{r}\mathrm{MM} \\
M M\end{array}$ & $\begin{array}{r}\text { FDN } \\
N D F\end{array}$ & $\begin{array}{l}\text { FDA } \\
A D F\end{array}$ \\
\hline \multicolumn{7}{|l|}{$\begin{array}{l}\text { Volumoso } \\
\text { Forage }\end{array}$} \\
\hline $\begin{array}{l}\text { Silagem de milho } \\
\text { Corn silage }\end{array}$ & 26,39 & 7,41 & 6,56 & 0,93 & 56,74 & 33,03 \\
\hline $\begin{array}{l}\text { Cana-de-açúcar } \\
\text { Sugar cane }\end{array}$ & 32,57 & 2,80 & 5,67 & 0,73 & 54,50 & 33,97 \\
\hline $\begin{array}{l}\text { Pastagem } \\
\text { Pasture }\end{array}$ & 36,25 & 5,40 & 5,35 & 2,76 & 70,09 & 38,76 \\
\hline \multicolumn{7}{|l|}{$\begin{array}{l}\text { Concentrado }{ }^{1} \\
\text { Concentrate }\end{array}$} \\
\hline $\begin{array}{l}\text { Silagem de milho }+\mathrm{NNP}^{2} \\
\text { Corn silage }+N P N\end{array}$ & 84,99 & $10,87^{(4)}$ & 7,94 & 1,15 & 22,57 & 4,99 \\
\hline $\begin{array}{l}\text { Silagem de milho }+ \text { Farelo de soja } \\
\text { Corn silage }+ \text { Soybean meal }\end{array}$ & 86,30 & 22,64 & 6,97 & 2,34 & 21,62 & 6,41 \\
\hline $\begin{array}{l}\text { Cana-de-açúcar + } \mathrm{NNP}^{2} \\
\text { Sugar cane }+ \text { Urea }\end{array}$ & 81,76 & 19,93 & 7,85 & 1,96 & 20,40 & 5,1 \\
\hline $\begin{array}{l}\text { Cana-de-açúcar + Farelo de soja }{ }^{3} \\
\text { Sugar cane + Soybean meal }\end{array}$ & 85,49 & 22,30 & 7,57 & 2,60 & 21,62 & 6,25 \\
\hline $\begin{array}{l}\text { Pastagem }+\mathrm{NNP}^{2} \\
\text { Pasture + Urea }\end{array}$ & 81,76 & 19,93 & 7,85 & 1,96 & 20,40 & 5,1 \\
\hline $\begin{array}{l}\text { Pastagem + Farelo de soja }{ }^{3} \\
\text { Pasture + Soybean meal }\end{array}$ & 85,49 & 22,30 & 7,57 & 2,60 & 21,62 & 6,25 \\
\hline
\end{tabular}


Tabela 3 - Volume médio de forragem disponível em cada período experimental

Table 3 - $\quad$ Mean forage volume availability in each experimental period

\begin{tabular}{lcc}
\hline $\begin{array}{l}\text { Período } \\
\text { experimental }\end{array}$ & Massa de & $\begin{array}{c}\text { Disponibilidade de } \\
\text { forragem (\% PC) }\end{array}$ \\
$\begin{array}{l}\text { Experimental } \\
\text { period }\end{array}$ & $\begin{array}{c}\text { Forage mass } \\
(\mathrm{kgDM} / \mathrm{ha})\end{array}$ & Forage \\
\hline
\end{tabular}

\begin{tabular}{lcc}
\hline $\begin{array}{l}\text { Período } 1 \text { (Agosto) } \\
\text { Period } 1 \text { (August) }\end{array}$ & 2.850 & 4,33 \\
$\begin{array}{l}\text { Período 2 (Setembro) } \\
\text { Period 2 (September) }\end{array}$ & 3.173 & 4,54 \\
$\begin{array}{l}\text { Período } 3 \text { (Outubro) } \\
\text { Period } 3 \text { (October) }\end{array}$ & 3.345 & 4,50 \\
$\begin{array}{l}\text { Período 4 (Novembro) } \\
\text { Period 4 (November) }\end{array}$ & 3.026 & 3,88 \\
Média & $3.098,5$ & 4,31 \\
Mean
\end{tabular}

carcaças, que foram pesadas individualmente ainda quentes;

- Espessura de gordura subcutânea (EG): medida à altura da $12^{\mathrm{a}}$ costela das meia-carcaças, com auxílio de um paquímetro, conforme a metodologia descrita por Müller (1987);

- Peso de corpo vazio (PCV): o peso vivo final (PVF) dos animais foi subtraído do conteúdo do trato gastrintestinal (TGI). O TGI de cada animal foi removido, pesado, esvaziado, lavado em água corrente e novamente pesado. Subtraindo o peso do TGI vazio do cheio, obteve-se o conteúdo do TGI;

- Peso de corpo vazio inicial: PCVI = PVI.0,912, em que PVI refere-se ao peso vivo inicial e o fator 0,912 significa que os animais referência apresentaram 8,79\% PV de conteúdo gastrintestinal;

- Peso de carcaça inicial: $\mathrm{PC}_{\mathrm{ar}} \mathrm{I}=$ PVI.0,4846, em que o fator 0,4846 significa que os animais referência apresentaram $48,46 \%$ de rendimento de carcaça.

- Rendimento de carcaça do peso do corpo vazio:

$\mathrm{RCarPCV}=\left(\frac{\mathrm{PCar}}{\mathrm{PCV}}\right) \cdot 100$,

em que $\mathrm{PC}_{\mathrm{ar}}$ é peso da carcaça e PCV, peso do corpo vazio.

- Rendimento de carcaça no ganho de peso:

RCarGP $=\left(\frac{\text { PCarF }- \text { PCarI }}{\text { GPVtotal }}\right) \cdot 100$,

em que $\mathrm{PC}_{\mathrm{ar}} \mathrm{F}$ = peso da carcaça final; $\mathrm{PC}_{\mathrm{ar}} \mathrm{I}=$ peso da carcaça inicial; GPVtotal = ganho de peso vivo total.

Adotou-se delineamento experimental de blocos casualizados em função do peso corporal inicial, com quatro repetições, em um arranjo fatorial 3 x 3 (três volumosos x três fontes protéicas). Os dados de ganho de peso diário foram analisados em esquema de parcelas subdivididas, em que os volumosos e as fontes nitrogenadas foram as parcelas principais e os períodos, as subparcelas.

Os dados foram analisados pelo procedimento "General Linear Model” (PROC GLM) do programa estatístico SAS (1995) e a comparação de médias, pelo teste Tukey, a 5\% de significância.

Todos os parâmetros foram avaliados tendo-se o peso corporal inicial como covariável, à exceção dos valores de espessura de gordura, que foram analisados tendo-se o peso corporal final como covariável.

\section{Resultados e Discussão}

Em razão de o consumo de pastagem ter sido estimado, a análise estatística foi realizada somente com as médias observadas com os animais que consumiram silagem de milho ou cana-de-açúcar (Tabela 4). Não houve interação significativa $(\mathrm{P}<0,05)$ fontes de volumoso $\times$ nitrogênio para a ingestão de MS total, assim como não foi observado efeito das fontes de volumoso e nitrogênio sobre esta variável.

Milton et al. (1997b) compararam o fornecimento de uréia, farelo de soja e farelo de algodão em dietas contendo milho laminado para novilhos em terminação. Os autores não observaram diferenças no consumo de MS entre os animais que receberam os diferentes tratamentos. Outros autores comparando fontes de nitrogênio não-protéico (uréia ou amiréia) com farelo de soja (Teixeira et al., 1999) ou farelo de algodão (Seixas et al., 1999) também não verificaram alterações no consumo de MS, semelhantemente ao observado neste trabalho.

De acordo com Macitelli et al. (2003a), o Amiferm pode substituir a uréia como fonte de NNP, não alterando o consumo de MS, nas quantidades diárias de 240 e $480 \mathrm{~mL}$. Porém, ao se injetar dose de $720 \mathrm{~mL}$ diretamente no rúmen, observou-se redução no consumo de MS de silagem de milho, resultado atribuído possivelmente às altas concentrações de amônia ruminal que, embora não-tóxicas, podem ter alterado o consumo por decréscimo no rendimento metabólico, decorrente da eliminação do excesso de amônia do organismo do animal.

Observou-se interação significativa $(\mathrm{P}<0,05)$ somente de período e fonte de volumoso (Tabela 5). Os animais alimentados com silagem de milho tiveram menor ganho de peso no terceiro período, o qual diferiu do primeiro. Não se observou diferença $(\mathrm{P}>0,05)$ sobre a variável GP/dia entre os períodos para os animais alimentados com cana-deaçúcar. Os animais mantidos em pastagem apresentaram 
Tabela 4 - Ingestão de MS total (IMS total - \% PV) proveniente de diferentes volumosos e fontes protéicas

Table 4 - Total DM intake (DMI total- \% BW) from different forage and nitrogen sources

\begin{tabular}{lc}
\hline $\begin{array}{l}\text { Volumoso } \\
\text { Forage }\end{array}$ & $\begin{array}{c}\text { IMS total }(\% \mathrm{PV}) \\
\text { DMI total }(\% \mathrm{BW})\end{array}$ \\
\hline $\begin{array}{l}\text { Cana-de-açúcar } \\
\text { Sugar cane }\end{array}$ & $1,67 \mathrm{a}$ \\
$\begin{array}{l}\text { Silagem de milho } \\
\text { Corn silage } \\
\text { Pastagem } \\
\text { Pasture }\end{array}$ & $1,78 \mathrm{a}$ \\
\hline
\end{tabular}

Fonte nitrogênio

Nitrogen source

\begin{tabular}{lc}
\hline Uréia & $1,78 \mathrm{a}$ \\
Urea & $1,63 \mathrm{a}$ \\
Amiferm & \\
Amifern & $1,76 \mathrm{a}$ \\
Farelo de soja & \\
Soybean meal &
\end{tabular}

Soybean meal

${ }^{1}$ O valor estimado por cálculos com base no ganho de peso médio diário, conforme AFRC (1995), não foi considerado na análise estatística.

Médias seguidas de letras diferentes diferem $(P<0,05)$ pelo teste Tukey; $\mathrm{CV}=8,13 \%$.

${ }^{1}$ Estimate value calculated by daily body weight according to AFRC (1995), was not included in the statistic analysis.

Means followed by different letters differ by Tukey test $(P<0.05) ; C V=8.13 \%$.

GP/dia semelhantes durante os três primeiros períodos, diferindo do quarto período, que apresentou menor GP/dia.

Ao analisar os resultados de GP/dia entre volumosos dentro de período, observou-se que, no primeiro e quarto períodos, os animais alimentados com silagem de milho apresentaram maiores ganhos de peso que os alimentados com cana-de-açúcar e os mantidos em pastagem, sendo que estes não diferiram entre si. No segundo e terceiro períodos, os diferentes volumosos proporcionaram GP/dia semelhantes.

O mesmo comportamento foi observado por Duarte et al. (1996), trabalhando com novilhos cruzados em confinamento que receberam à vontade silagem de milho, silagem de sorgo ou cana-de-açúcar, mais $2 \mathrm{~kg} /$ animal/dia de uma ração concentrada. Os ganhos foram de 1,199; 1,185 e 0,642 kg/dia, quando alimentados com silagem de milho, silagem de sorgo e cana-de-açúcar, respectivamente. De acordo com San Thiago \& Vieira (2002), a substituição da silagem de milho ou de sorgo pela cana, como forma de reduzir custos com alimentação de animais em engorda confinados, resultará provavelmente em decréscimo no desempenho animal. Apesar disso, os autores consideram que a cana-de-açúcar pode ser uma opção ao volumoso na engorda de animais zebu, que iniciam a esta fase com idade acima de 30 meses, ou em situações nas quais se disponibilizam ingredientes para concentrados mais econômicos (San Thiago \& Vieira, 2002).
Tabela 5 - Ganho de peso médio diário ( $\mathrm{kg} / \mathrm{dia})$ dos animais alimentados com diferentes volumosos e fontes protéicas nos quatro períodos experimentais

Table 5 - $\quad$ Average daily weight gain ( $\mathrm{kg} /$ day) of animals fed different forages and nitrogen source in the four experimental periods

\begin{tabular}{|c|c|c|c|c|c|}
\hline \multirow[t]{2}{*}{ Item } & \multicolumn{4}{|c|}{$\begin{array}{l}\text { Período } \\
\text { Period }\end{array}$} & \multirow[b]{2}{*}{$\begin{array}{l}\text { Média } \\
\text { Mean }\end{array}$} \\
\hline & 1 & 2 & 3 & 4 & \\
\hline \multicolumn{6}{|l|}{$\begin{array}{l}\text { Volumoso } \\
\text { Forage }\end{array}$} \\
\hline $\begin{array}{l}\text { Cana-de-açúcar } \\
\text { Sugar cane }\end{array}$ & $0,92 \mathrm{Aa}$ & $0,81 \mathrm{Aa}$ & $0,90 \mathrm{Aa}$ & $0,71 \mathrm{Aa}$ & $0,83 b$ \\
\hline $\begin{array}{l}\text { Silagem de milho } \\
\text { Corn silage }\end{array}$ & $1,34 \mathrm{Ab}$ & 1,11ABa & 0,89Bа & $1,04 \mathrm{ABb}$ & $1,09 \mathrm{a}$ \\
\hline $\begin{array}{l}\text { Pastagem } \\
\text { Pasture }\end{array}$ & $0,89 \mathrm{Aa}$ & $0,86 \mathrm{Aa}$ & $1,02 \mathrm{Aa}$ & $0,50 \mathrm{Ba}$ & $0,82 b$ \\
\hline
\end{tabular}

Fonte nitrogênio

Nitrogen source

$\begin{array}{lccccc}\text { Uréia } & 1,11 \mathrm{Aa} & 0,94 \mathrm{Aa} & 0,97 \mathrm{Aa} & 0,75 \mathrm{Aa} & 0,94 \mathrm{a} \\ \begin{array}{l}\text { Urea } \\ \text { Amiferm } \\ \text { Amiferm }\end{array} & 0,87 \mathrm{Aa} & 0,92 \mathrm{Aa} & 0,81 \mathrm{Aa} & 0,70 \mathrm{Aa} & 0,83 \mathrm{a} \\ \begin{array}{l}\text { Farelo de soja } \\ \text { Soybean meal } \\ \begin{array}{l}\text { Média } \\ \text { Mean }\end{array}\end{array} & 1,17 \mathrm{Aa} & 0,92 \mathrm{Aa} & 1,02 \mathrm{Aa} & 0,79 \mathrm{Aa} & 0,97 \mathrm{a} \\ & 1,05 \mathrm{~A} & \text { 0,93A } & \text { 0,93A } & 0,75 \mathrm{~B} & 0,91 \\ \end{array}$

Médias seguidas de diferentes letras minúsculas na linha e maiúsculas na coluna para volumosos e fontes de nitrogênio diferem $(P<0,05)$ pelo teste Tukey. CV $=31,07 \%$.

Means followed by different small/capital letters within a row/column for forage and nitrogen source differ $(P<0.05)$ by Tukey test. $C V=31.07 \%$.

Os ganhos de peso observados neste trabalho foram semelhantes aos relatados por Santos (2004), de 0,915 kg/ dia, ao fornecer suplemento na quantidade de $1 \% \mathrm{PV}$ a novilhos F1 Limousin x Nelore em pastagem de Brachiaria decumbens. Da mesma forma, Zervoudakis et al. (2001) observaram ganhos de $0,985 \mathrm{~kg} /$ dia para novilhos mestiços Holandês x Zebu mantidos em pastagem de Brachiaria decumbens recebendo suplemento em quantidade semelhante à adotada neste estudo. Vale ressaltar que ambos os trabalhos apresentaram disponibilidade de MS de massa forrageira (7.902 e $6.836 \mathrm{~kg} / \mathrm{ha}$, respectivamente) maior que a desta pesquisa $(3.098,5 \mathrm{~kg})$. Andrade \& Alcalde (1995) relataram disponibilidade de MS mínima de 3\% do peso vivo/dia para se obter adequada suplementação. Infere-se, portanto, que a quantidade de forragem disponível neste trabalho (4,31\% do peso vivo) não foi limitante ao desempenho animal, pois possibilitou consumo irrestrito e seletivo aos animais. No entanto, a menor qualidade da pastagem em relação à silagem de milho (menor teor de proteína e maiores quantidades de FDN e FDA) e o provável menor consumo de pastagem (1,08 x 1,19\% PV, dados não apresentados) devem ter acarretado menor digestibilidade da 
pastagem e menor quantidade de nutrientes disponíveis para o desempenho dos animais alimentados com capim.

Não foi observada diferença significativa $(\mathrm{P}>0,05)$ entre as fontes de nitrogênio para GP/dia (Tabela 5). Seixas et al. (1999) também não observaram diferenças significativas $(\mathrm{P}>0,05)$ nas médias de ganho de peso diário, ao utilizarem diferentes fontes protéicas para bovinos confinados com silagem de milho, com valores de 1,14; 1,17 e 1,23 kg para farelo de algodão, uréia e Amiréia, respectivamente. Em contrapartida, Milton et al. (1997a) compararam o fornecimento de uréia, farelo de soja e farelo de algodão em dietas contendo milho laminado, para novilhos em terminação. Esses autores observaram que os animais alimentados com farelo de soja apresentaram eficiência alimentar $9 \%$ superior e ganharam peso $13 \%$ mais rápido que os suplementados com uréia. Os parâmetros metabólicos indicaram maior fluxo de nitrogênio microbiano, bem como maior eficiência da síntese de proteína microbiana para o farelo de soja.

Henrique et al. (2005) observaram que o subproduto concentrado da produção de lisina, um produto similar ao Amiferm, pode ser utilizado como alimento para tourinhos em confinamento em níveis de até 3,7\% da MS da dieta, permitindo ganhos em torno de $1,1 \mathrm{~kg} /$ dia. Da mesma forma, substituindo a uréia pelo subproduto da produção de lisina (SPL) na dieta de bovinos confinados com silagem de milho, Oliveira et al. (2000) observaram ganhos de peso de 1,07 kg/ dia para os animais alimentados com $300 \mathrm{~mL}$ de SPL, 0,64 kg para os que receberam $600 \mathrm{~mL}$ e $0,87 \mathrm{~kg}$ para aqueles alimentados com $600 \mathrm{~mL}$ juntamente com caldo de cana-deaçúcar concentrado. A adição na dieta de uma fonte de carboidrato rapidamente fermentável é fundamental para boa eficiência de utilização da amônia formada no rúmen. Este fato é mais relevante no caso do Amiferm, que apresenta rápida solubilização ruminal após a ingestão, superior inclusive à solubilização da uréia (Macitelli et al., 2003b). Henrique et al. (2005) e Macitelli et al. (2003a,b) sugerem que esses produtos podem substituir totalmente o nitrogênio não-protéico e parte do nitrogênio protéico, desde que o balanceamento da dieta seja adequado e sejam utilizadas dietas com adequado teor de energia e volumoso de boa qualidade.

Silva et al. (2002), ao estimarem as exigências de PB ruminal degradável e não-degradável de bovinos Nelore de diferentes pesos, concluíram que, à medida que se eleva o peso vivo dos animais, maior pode ser a participação de proteína degradável no rúmen para o suprimento das exigências totais de $\mathrm{PB}$, indicando que, para animais em fase de terminação, maiores níveis de NNP podem ser utilizados na dieta. Este resultado corrobora os dados encontrados nesta pesquisa, que podem ser justificados pelo fato de, nesta fase, o perfil de aminoácidos não ser limitante ao ganho de peso e, ainda, segundo Silva et al. (2002), o retorno econômico ser mais satisfatório.

Observando-se as médias de GP/dia nos períodos, para os volumosos e as fontes protéicas, nota-se que apenas o quarto período diferiu $(\mathrm{P}<0,05)$ dos demais, supondo-se que os animais já haviam alcançado o peso ideal para abate e seu limite genético para ganho de peso. Quando o GP/dia começa a declinar, na maioria das vezes, a suplementação e/ou confinamento tornam-se anti-econômicos, pois os ganhos de peso obtidos não cobrem os custos. Altos níveis de suplementação para animais adultos, como neste trabalho (30 meses de idade), não é uma alternativa viável, em virtude da baixa resposta em ganho de peso.

Não foi observada interação $(\mathrm{P}>0,05)$ fontes de nitrogênio $\times$ volumoso para essas variáveis (Tabela 6 ); portanto, os dois efeitos foram considerados independentes. Não foram verificadas diferenças $(\mathrm{P}>0,05)$ para PVI, $\mathrm{PC}_{\mathrm{ar}} \mathrm{I}$ e PCVI dos animais submetidos aos dife-rentes volumosos e fontes de nitrogênio (Tabela 6). Notou-se, para os animais alimentados com os diferentes volumosos, diferença significativa $(\mathrm{P}<0,05)$ para o $\mathrm{PVF}$ e $\mathrm{PC}_{\mathrm{ar}} \mathrm{F}$, sendo superior para os animais que receberam silagem de milho e menor para os alimentados com cana-de-açúcar, sendo que estes não diferiram dos que permaneceram na pastagem. $\mathrm{O} \mathrm{GC}_{\mathrm{ar}} /$ dia dos animais alimentados com silagem de milho, por sua vez, foi superior $(\mathrm{P}<0,05)$ ao obtido nos animais recebendo cana-de-açúcar, que não diferiram daqueles mantidos em pastagem.

Da mesma forma, Vaz \& Restle (2005) observaram que os novilhos Hereford alimentados com ração à base de silagem de milho apresentaram maior peso de abate que aqueles recebendo cana-de-açúcar (446 vs 421 kg). Brondani \& Restle (1991), fornecendo ração com silagem de milho ou cana-de-açúcar a novilhos Charoleses confinados, verificaram maior velocidade de crescimento nos animais que receberam aquele ingrediente, atingindo peso de abate de $420 \mathrm{~kg}$ aos 88 dias de confinamento. Os novilhos que receberam cana-de-açúcar atingiram este peso somente após 110 dias de confinamento, fato explicado pelos menores teores de proteína e fibra deste volumoso.

O PVF e o PCVF dos animais alimentados com Amiferm foram menores $(\mathrm{P}<0,05)$ que os obtidos naqueles alimentados com farelo de soja ou uréia, que não diferiram $(\mathrm{P}>0,05)$ entre si (Tabela 6). O PC $\mathrm{ar}_{\mathrm{F}} \mathrm{F}$ dos animais alimentados com uréia não diferiu $(\mathrm{P}>0,05)$ daqueles que receberam Amiferm e farelo de soja, que apresentaram diferença significativa $(\mathrm{P}<0,05)$ entre si. 
Tabela 6 - Peso vivo inicial (PVI), peso da carcaça inicial $\left(\mathrm{PC}_{\mathrm{ar}} \mathrm{l}\right)$, peso do corpo vazio inicial (PCVI), peso vivo final (PVF), peso da carcaça final $\left(\mathrm{PC}_{\mathrm{ar}} \mathrm{F}\right)$, peso do corpo vazio final $(\mathrm{PCVF})$ e ganho de carcaça diário $\left(\mathrm{GC}_{\mathrm{ar}} / \mathrm{dia}\right)$ dos animais alimentados com diferentes volumosos e fontes protéicas

Table 6 - Initial body weight (IBW), initial carcass weight (IC $\left.C_{a r} W\right)$, initial empty body weight (IEBW), final live weight (FLW), final carcass weight ( $\left.F C_{\text {ar }} W\right)$, final empty body weight (FEBW) and daily carcass gain $\left(D C_{a r} G\right)$ of animals fed different forages and nitrogen sources

\begin{tabular}{|c|c|c|c|c|c|c|c|}
\hline Item & $\begin{array}{l}\text { PVI } \\
I L W\end{array}$ & $\begin{array}{l}\mathrm{PC}_{\mathrm{ar}} \mathrm{I} \\
I C_{\mathrm{ar}} W\end{array}$ & $\begin{array}{l}\text { PCVI } \\
I E B W\end{array}$ & $\begin{array}{l}\text { PVF } \\
F L W\end{array}$ & $\begin{array}{l}\mathrm{PC}_{\mathrm{ar}} \mathrm{F} \\
F C_{\mathrm{ar}} W\end{array}$ & $\begin{array}{l}\text { PCVF } \\
F E B W\end{array}$ & $\begin{array}{c}\mathrm{GC}_{\mathrm{ar}} / \mathrm{dia} \\
D C_{\mathrm{ar}} G\end{array}$ \\
\hline \multicolumn{8}{|l|}{ Volumoso } \\
\hline $\begin{array}{l}\text { Cana-de-açúcar } \\
\text { Sugarcane }\end{array}$ & 359,08 & 174,01 & 327,05 & $465,67 a$ & $233,70 a$ & $428,92 a$ & $0,47 a$ \\
\hline $\begin{array}{l}\text { Silagem de milho } \\
\text { Corn silage }\end{array}$ & 373,92 & 181,20 & 340,56 & $499,25 b$ & $258,13 b$ & $471,90 \mathrm{~b}$ & $0,61 b$ \\
\hline $\begin{array}{l}\text { Pastagem } \\
\text { Pasture }\end{array}$ & 379,25 & 183,78 & 345,42 & 480,83ab & $246,55 a b$ & $453,86 b$ & $0,50 \mathrm{ab}$ \\
\hline \multicolumn{8}{|c|}{$\begin{array}{l}\text { Fonte de nitrogênio } \\
\text { Nitrogen source }\end{array}$} \\
\hline $\begin{array}{l}\text { Uréia } \\
\text { Urea }\end{array}$ & 368,33 & 178,49 & 335,48 & $490,50 \mathrm{~b}$ & $248,29 a b$ & $458,97 b$ & $0,55 a b$ \\
\hline $\begin{array}{l}\text { Amiferm } \\
\text { Amiferm }\end{array}$ & 364,33 & 176,55 & 331,84 & 461,83a & $234,41 \mathrm{a}$ & $434,72 a$ & $0,46 \mathrm{a}$ \\
\hline $\begin{array}{l}\text { Farelo de soja } \\
\text { Soybean meal }\end{array}$ & 379,58 & 183,94 & 345,72 & $493,42 b$ & $255,68 b$ & $460,99 b$ & $0,57 b$ \\
\hline CV (\%) & 5,56 & 2,25 & 5,55 & 4,47 & 5,32 & 4,88 & 19,67 \\
\hline
\end{tabular}

Médias seguidas de diferentes letras nas colunas para volumosos e fontes de nitrogênio diferem $(P<0,05)$. pelo teste de Tukey. Means followed by the different letter within a column for forage and nitrogen source differ $(P<0.05)$ by Tukey test.

Não se observou efeito $(P>0,05)$ da interação fonte de volumoso $\times$ nitrogênio sobre rendimento de carcaça $\left(\mathrm{RC}_{\mathrm{ar}}\right)$, rendimento de carcaça em função do peso do corpo vazio $\left(\mathrm{RC}_{\mathrm{ar}} \mathrm{PCV}\right)$, rendimento de carcaça do ganho de peso $\left(R_{a r} G P V\right)$ e espessura de gordura (EG) (mm) (Tabela 7).

Os resultados deste experimento corroboram os observados por Vaz \& Restle (2005), em que o rendimento de carcaça de novilhos alimentados com cana-de-açúcar ou silagem de milho não foi afetado pelo tipo de volumoso utilizado na dieta, com valores médios de 50,1 e 51,5\%, respectivamente, apesar de se esperar menor rendimento de carcaça em animais alimentados com volumosos mais fibrosos, em virtude das diferenças no desenvolvimento do trato digestório, na velocidade de passagem do alimento pelo trato (Di Marco, 1998) e no arqueamento de costelas. Estudando novilhos Guzerá suplementados em confinamento com silagem de milheto, cana-de-açúcar, cana-de-açúcar com probiótico, cana-de-açúcar hidrolisada ou silagem de milho, Oliveira et al. (2001) verificaram similaridade no rendimento de carcaça dos animais, de 53,30; 53,28; 53,42; 54,59 e $54,04 \%$, respectivamente.

Milton et al. (1997b) verificaram que o peso e o rendimento de carcaça quente, em novilhos de ano cruzados, suplementados em confinamento com diferentes níveis de uréia, responderam de forma significativa à adição de uréia à dieta. O peso da carcaça dos animais que receberam uréia foi $6,6 \mathrm{~kg}$ maior em relação aos que não receberam. A espessura de gordura subcutânea aumentou linearmente conforme o acréscimo do nível de uréia adicionado à dieta.

A espessura de gordura não apresentou diferença significativa $(\mathrm{P}>0,05)$ entre as fontes de nitrogênio e os volumosos (Tabela 7). Os valores de espessura de gordura encontrados neste estudo podem ser considerados excessivos (acima de $7 \mathrm{~mm}$ ), uma vez que admite-se que a espessura de gordura entre 3 e 5 mm é suficiente para garantir boa proteção às carcaças resfriadas contra a desidratação no resfriamento da carcaça e o escurecimento da carne.

De acordo com Rattray \& Joyce, citados por Silva et al. (2002), ganhos de peso associados com altas deposições de gordura não energeticamente mais eficientes, porém menos eficientes em relação à conversão de alimentos em peso vivo. Isso ocorre, segundo estes autores, porque os tecidos adiposos, nos quais ocorre grande parte do aumento de peso vivo, contêm teores mais elevados de matéria seca que os músculos (cerca de $80 \%$ e $30 \%$, respectivamente).

O excesso de gordura subcutânea demonstra claramente que os animais já haviam alcançado o peso ideal de abate antes do término do período experimental, uma vez que a gordura subcutânea (principalmente em animais cruzados) é a última a ser depositada. Perón et al. (1993) ressaltam que há evidências científicas de que a distribuição relativa da gordura entre os depósitos corporais pode afetar as exigências energéticas dos bovinos. Fortalecendo essa afirmação, Thompson et al. (1983) relataram que a 
Tabela 7 - Rendimento de carcaça $\left(\mathrm{RC}_{\mathrm{ar}}\right.$ \%), rendimento de carcaça em função do peso do corpo vazio $\left(\mathrm{RC}_{\mathrm{ar}} \mathrm{PCV}\right.$, $\%)$, rendimento de carcaça do ganho de peso $\left(\mathrm{RC}_{\mathrm{ar}} \mathrm{GP}\right.$, $\%$ ) e espessura de gordura (EG, $\mathrm{mm}$ ) de animais os alimentados com diferentes volumosos e fontes protéicas

Table 7 - Carcass yield ( $\left.C_{a r} Y \%\right)$, carcass yield in empty body weight $\left(C_{a r} Y E B W \%\right)$, carcass yield of the weight gain $\left(C_{a r} Y W G \%\right) e$ and layer fat (LFmm) of animals fed different forages and nitrogen sources

\begin{tabular}{|c|c|c|c|c|}
\hline Item & $\begin{array}{l}\mathrm{RC}_{\mathrm{ar}}(\%) \\
C_{a r} Y(\%)\end{array}$ & $\begin{array}{c}\mathrm{RC}_{\mathrm{ar}} \mathrm{PCV}(\%) \\
C_{a r} \mathrm{YEBW}(\%)\end{array}$ & $\begin{array}{c}\mathrm{RC}_{\mathrm{ar}} \mathrm{GP} \\
C_{a r} Y W G(\%)\end{array}$ & $\begin{array}{c}\mathrm{EG}(\mathrm{mm}) \\
L F(\mathrm{~mm})\end{array}$ \\
\hline \multicolumn{5}{|l|}{$\begin{array}{l}\text { Volumoso } \\
\text { Forage }\end{array}$} \\
\hline $\begin{array}{l}\text { Cana-de-açúcar } \\
\text { Sugarcane }\end{array}$ & 50,18 & 54,48 & 56,17 & 9,47 \\
\hline $\begin{array}{l}\text { Silagem de milho } \\
\text { Corn silage }\end{array}$ & 51,71 & 54,72 & 61,77 & 8,75 \\
\hline $\begin{array}{l}\text { Pastagem } \\
\text { Pasture }\end{array}$ & 51,21 & 54,26 & 62,35 & 7,46 \\
\hline \multicolumn{5}{|c|}{$\begin{array}{l}\text { Fonte de nitrogênio } \\
\text { Nitrogen source }\end{array}$} \\
\hline $\begin{array}{l}\text { Uréia } \\
\text { Urea }\end{array}$ & 50,58 & 54,48 & 56,78 & 8,07 \\
\hline $\begin{array}{l}\text { Amiferm } \\
\text { Amiferm }\end{array}$ & 50,76 & 54,72 & 60,17 & 9,15 \\
\hline $\begin{array}{l}\text { Farelo de soja } \\
\text { Soybean meal }\end{array}$ & 51,76 & 54,26 & 63,33 & 8,45 \\
\hline CV (\%) & 3,84 & 3,78 & 14,62 & 35,82 \\
\hline
\end{tabular}

atividade metabólica do tecido adiposo interno parece ser maior que a do tecido adiposo periférico (subcutâneo), acarretando diferenças no requerimento de energia para a manutenção. Ao considerar essas afirmações, pode-se justificar, em parte, o menor ganho de peso diário observado de animais mais velhos e com grande quantidade de gordura corporal.

Os ganhos de peso alcançados nesta pesquisa foram menores que os calculados, fato explicado pelos seguintes fatores: os animais não possuíam potencial genético para o ganho de peso estimado; o alimento não apresentava a energia suposta nas formulações das dietas; e havia excesso de gordura que, de acordo com Thompson et al. (1983) e Owens et al. (1995), pode acarretar maiores exigências de energia para mantença.

\section{Conclusões}

Independentemente da fonte de volumoso, a uréia e o Amiferm podem substituir o farelo de soja na terminação de bovinos com mais de 30 meses, sem comprometimento do ganho de peso e das características da carcaça. Da mesma forma, o uso de Amiferm pode ser uma alternativa à utilização da uréia, dependendo da disponibilidade local e do custo.
A qualidade do volumoso exerce efeito significativo sobre o ganho de peso na terminação de bovinos adultos, mas sem alterar o rendimento de carcaça.

\section{Literatura Citada}

AGRICULTURAL AND FOOD RESEARCH COUNCIL - AFRC. Technical committee on responses to nutrients, energy and protein requirements of ruminants. Wallinford: $C A B$ International, 1995. 159p.

ANDRADE, P.; ALCALDE, C.R. Nutrição e alimentação de novilho precoce. In: ENCONTRO NACIONAL SOBRE NOVILHO PRECOCE, 1995, Campinas. Anais... Campinas: 1995. p.93-110.

BRONDANI, I.L.; RESTLE, J. Efeito das dietas contendo cana-deaçúcar ou silagem de milho no desempenho de novilhos em confinamento. Ciência Rural, v.21, n.1, p.129-134, 1991.

DI MARCO, O.N. Crecimiento de vacunos para carne. Mar Del Plata: Oscar N. Di Marco, 1998. 246p.

DUARTE, J.O.; MONTEIRO, J.A.; MIRANDA, J.E.C. et al Resultados financeiros de confinamento de bovinos alimentados com silagens de milho e sorgo e capim. In: CONGRESSO NACIONAL DE MILHO E SORGO, 21., 1996, Londrina. Resumos... Londrina: Associação Brasileira de Milho e Sorgo, 1996. p.334.

ETHERIDGE, R.D.; PESTI, G.M.; FOSTER, E.H. A comparison of nitrogen values obtained utilizing the Kjeldahl nitrogen and Dumas combustion methodologies (Leco CNS 2000) on samples typical of an animal nutrition analytical laboratory. Animal Feed Science and Technology, v.73, p.21-28, 1998.

HENRIQUE, W.; LEME, P.R.; LANNA, D.P.D. et al. Níveis do subproduto concentrado da produção de lisina em dietas com alto concentrado para tourinhos Santa Gertrudes em terminação. Revista Brasileira de Zootecnia, v.34, n.6, p.2457-2465, 2005 (supl.).

MACITELLI, F.; BERCHIELLI, T.T.; ANDRADE, P. et al. Avaliação do resíduo da produção do glutamato monossódico (Amiferm) como fonte de nitrogênio não protéico para bovinos em pastagem de Brachiaria brizantha (Hochst) Stapf cv Marandu. Archivos Latinoamericanos de Producción Animal, v.11, n.2, p.119124, 2003b.

MACITELLI, F.; BERCHIELLI, T.T.; ANDRADE, P. et al. Influência do resíduo da produção do glutamato monossódico (Amiferm) sobre os parâmetros ruminais e o consumo de bovinos alimentados com silagem de milho. Archivos Latinoamericanos de Producción Animal, v.11, n.2, p.111-118, 2003a.

McMENIMAN, N.P. Methods of estimating intake of grazing animals. In: REUNIÃO ANUAL DA SOCIEDADE BRASILEIRA DE ZOOTECNIA, 34., 1997, Juiz de Fora. Anais... Juiz de Fora: Sociedade Brasileira de Zootecnia, 1997. p.131-168.

MILTON, C.T.; BRANDT JR., R.T.; TITGEMEYER, E.C. et al. Effect of degradable and escape protein and roughage type on performance and carcass characteristics of finishing yearling steers. Journal of Animal Science, v.75, p.2834-2840, 1997b.

MILTON, C.T.; BRANDT JR., R.T.; TITGEMEYER, E.C. Urea in dry-rolled corn diets: finishing steer performance, nutrient digestion, and microbial protein production. Journal of Animal Science, v.75, p.1415-1424, 1997a.

MÜLLER, L. Normas para avaliação de carcaças e concurso de carcaça de novilhos. 2.ed. Santa Maria: Universidade Federal de Santa Maria, 1987. 31p.

OLIVEIRA, B.Y.S.; ALVES, J.B.; BERGAMASCHINE, A.F. et al. Desempenho do bovinos terminados em confinamento, com diferentes volumosos. In: REUNIÃO ANUAL DA SOCIEDADE BRASILEIRA DE ZOOTECNIA, 38., 2001, Piracicaba. Anais... Piracicaba: Sociedade Brasileira de Zootecnia, 2001. (CD-ROM). 
OLIVEIRA, D.J.C.; BERGAMASCHINE, A.F.; ALVES, J.B. Avaliação do subproduto da produção de lisina para bovinos - digestibilidade das dietas e desempenho em confinamento. Ciência Agrotécnica, v.24, n.3, p.756-765, 2000.

OWENS F.N.; ZINN, R. Metabolismo de la proteina em los ruminants. In: $\mathrm{CHURCH}$, C.D. (Ed.) El rumiante: fisiologia digestiva y nutrición. Zaragoza: Acribia, 1988. p.255-282.

OWENS, F.N.; GILL, D.R.; SECRIST, D.S. et al. Review of some aspects of growth and development of feedlot cattle. Journal of Animal Science, v.73, n.10, p.3152-3172, 1995.

PERÓN, A.J.; FONTES, C.A.A.; LANA, R.P. et al. Tamanho de órgãos internos e distribuição da gordura corporal, em novilhos de cinco grupos genéticos, submetidos à alimentação restrita e ad libitum. Revista da Sociedade Brasileira de Zootecnia, v.22, n.5, p.813-819, 1993.

RUSSEL, J.B.; O'CONNOR, J.D.; FOX, D.G. et al. A net carbohydrate and Protein System for evaluating cattle diets: I. Ruminal fermentation. Journal of Animal Science, v.70, p.3551-3561, 1992.

SAN THIAGO, L.R; VIEIRA, J.M. [2002]. Cana-de-açúcar: uma alternativa de alimento para a seca. Disponível em: <http:// www.cnpgc.embrapa.br/publicacoes/cot/COT73.html> Acesso em: $10 / 7 / 2006$

SANTOS, E.D.G.; PAULINO, M.F.; VALADARES FILHO, S.C. et al. Terminação de tourinhos Limousin x Nelore em pastagem diferida de Brachiaria Decumbens Stapf, durante a estação seca, alimentados com diferentes concentrados. Revista Brasileira de Zootecnia, v.33, n.6, p.1627-1637, 2004.

STATISTICAL ANALISYS SYSTEM - SAS. User's guide: statistics. 5ed. Cary: 1995. 1290p.

SEIXAS, J.R.C.; EZEQUIEL, J.M.B.; ARAÚJO, W.D. et al. Desempenho de bovinos confinados alimentados com dietas à base de farelo de algodão, uréia ou amiréia. Revista Brasileira de Zootecnia, v.28, n.2, p.432-438, 1999.

SIBERT, B.D.; HUNTER, R.A Supplementary feeding of grazing animals. In: HACKER, J.B. (Ed.) Nutritional limits to animal production from pastures. Melbourne: CSIRO, 1982. p.409-426.

SILVA, D.J. Análise de alimentos: métodos químicos e biológicos. Viçosa, MG: Universidade Federal de Viçsoa, 1990. 165p.
SILVA, F.F.; VALADARES FILHO, S.C.; ÍTAVO, L.C.V. et al. Composição corporal e requisitos energéticos e protéicos de bovinos Nelore, não castrados, alimentados com rações contendo diferentes níveis de concentrado e proteína. Revista Brasileira de Zootecnia, v.31, n.1, p.503-513, 2002 (supl.).

TEIXEIRA, J.C.; DELGADO, E.F; CORREA, E.M. et al. Cinética da digestão ruminal da amiréia 45-S em vacas da raça holandesa. Ciência e Agrotecnologia, v.23, n.3, p.719-723, 1999.

THOMPSON, W.R.; MEISKE, J.C.; GOODRICH, R.D. et al. Influence of body composition on energy requirement of breed cows during winter. Journal of Animal Science, v.56, n.5, p.1241-1252, 1983.

Van SOEST, P.J.; ROBERTSON, J.B.; LEWIS, B.A. Methods for dietary fiber, neutral detergent fiber, and nonstarch polysaccharides in relation to animal nutrition. Journal of Dairy Science, v.74, n.10, p.3583-3597, 1991.

VAZ, F.N.; RESTLE, J.; ALVES FILHO, D.C. et al. Peso das vísceras e rendimento de carcaças de novilhos ou novillas Braford superprecoces, terminados com suplementação em pastagem cultivada sob pastejo controlado. In: REUNIÃO ANUAL DA SOCIEDADE BRASILEIRA DE ZOOTECNIA, 38., 2001, Piracicaba, Anais... Piracicaba: Sociedade Brasileira de Zootecnia. 2001. (CD-ROM).

VAZ, F.N.; RESTLE, J. Características de carcaça e da carne de novilhos Hereford terminados em confinamento com diferentes fontes de volumoso. Revista Brasileira de Zootecnia, v.34, n.1, p.230-238, 2005.

ZERVOUDAKIS, J.T.; PAULINO, M.F.; DETMANN, E. et al. Desempenho e características de carcaça de novilhos suplementados no período das águas. Revista Brasileira de Zootecnia, v.30, n.4, p.1381-1389, 2001. 